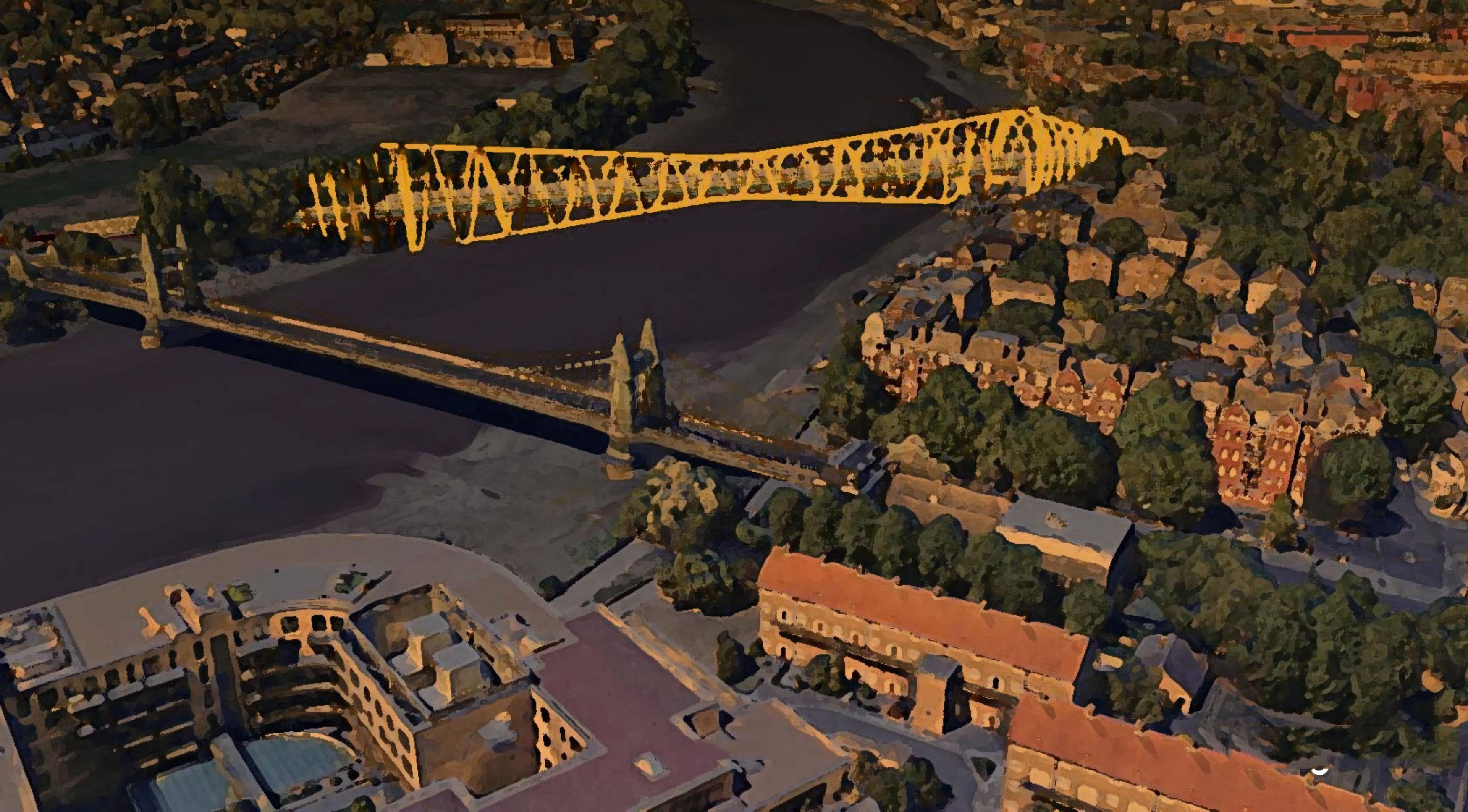




\title{
AN IDEA FOR HAMMERSMITH BRIDGE ISSUE
}

\author{
Seyed Mohyeddin Seghatoleslam \\ Researcher, Architectural \& Urban Designer \\ seghatoleslam@outlook.com \\ $15 / 11 / 2019$
}

\begin{abstract}
The 132-year-old Hammersmith Bridge has been closed to motor traffic since April 2019. This beautiful suspension structure needs to be seriously repaired again. Although the bridge was significantly damaged by the bombings of 1939, 1996 and 2000, it has continued to serve the community successfully. Hammersmith Bridge is a beautiful example of innovation $19^{\text {th }}$ century British Engineering and is an iconic structure in West London.
\end{abstract}

This paper contains a summary description of the existing bridge issue and proposed solution. Different design options are summarised, and a sketch of a new bridge is proposed.

KEYWORDS: Existing Hammersmith bridge, proposed structure, modern bridge, beautiful suspension structure, closed bridge, structures retirement, green bridge, viewing platform, recreational area, point of interest

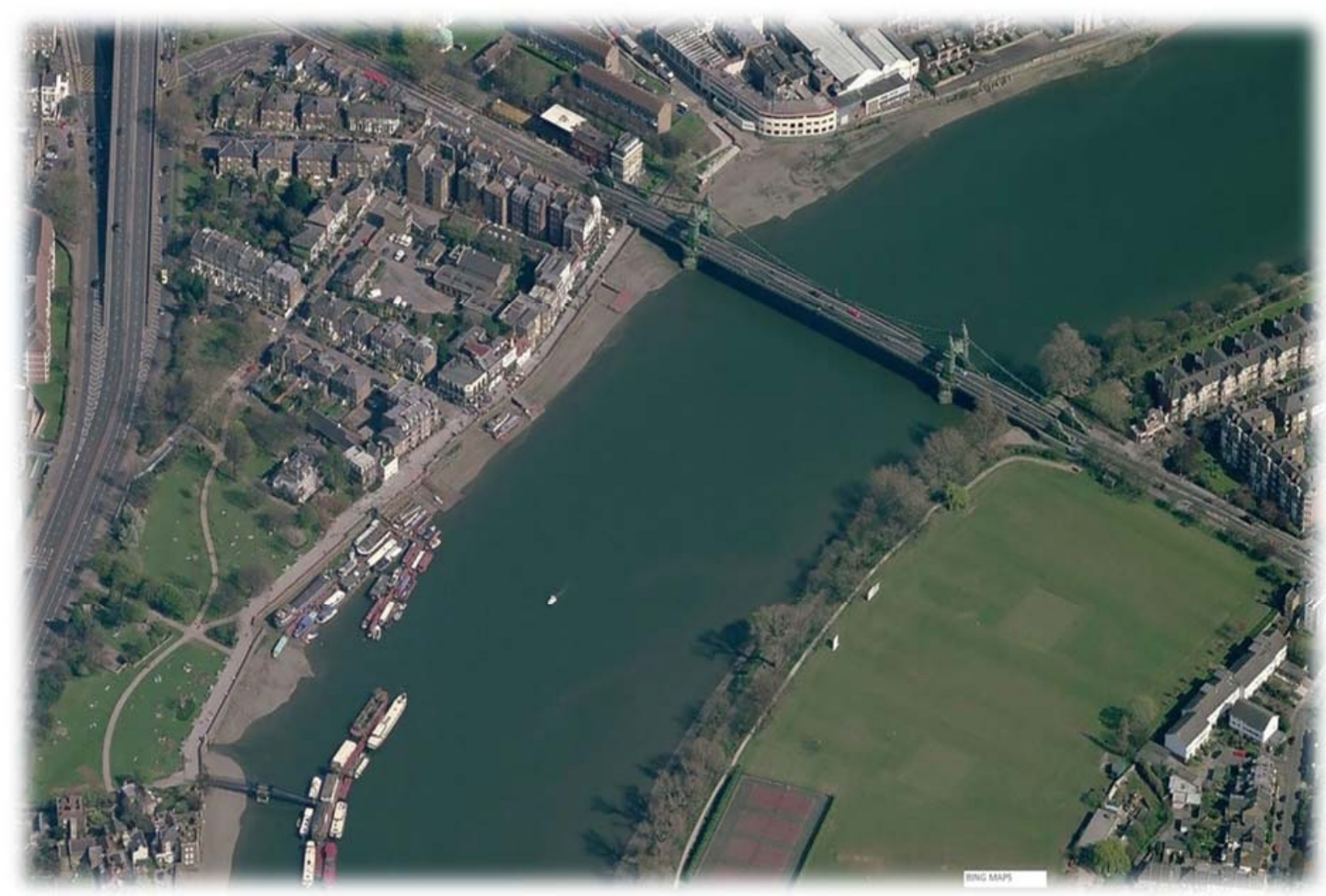

FIGURE 1: EXISTING HAMMERSMITH BRIDGE 


\section{INTRODUCTION}

Hammersmith Bridge located in the London Borough of Hammersmith \& Fulham (LBHF) and is a three-span suspension bridge.

$>$ Hammersmith-side (North) Span 46.9m

$>$ Main Span $128.6 \mathrm{~m}$

$>$ Barnes-side (South) Span 47.9m

The total length of existing Hammersmith Bridge is $223.4 \mathrm{~m}$. The bridge sits on two abutments and two piers. The span has no skew.

It connects Hammersmith Bridge Road to Castelnau in North Barnes, passing over the River Thames in west London.

The bridge was declared a Grade II* listed structure in 2008 for the following principal reasons: "The architectural quality of Hammersmith Bridge is remarkable in both form, with its monumental towers, and ornamentation, as seen in the lavish colour scheme and heraldry; the bridge is one of the most distinctive on the Thames" ${ }^{[1]}$.

Hammersmith Bridge has a total width of $13.1 \mathrm{~m}$ with $8.2 \mathrm{~m}$ clear carriageway formed from wrought-iron girders and two footways either side.

The bridge reopened to a 7.5-tonne weight restriction after structural repair works were undertaken in 1997.

Hammersmith Bridge was closed to all motor traffic in April 2019 after cracks were discovered in the bridge's pedestals, the footing which support the structure.

Transport for London (TfL) and Hammersmith \& Fulham (H\&F) Council estimate the work could cost $f 120 \mathrm{~m}$ and is expected to take approximately three years. This bridge connects the north Barnes area to Hammersmith area and plays a vital role in these two regions, especially for the north Barnes area.

\section{SUMMARY OF THE PROBLEM AND PROPOSED SOLUTION}

The damage that the closed bridge has caused to the businesses of these two regions (Hammersmith and North Barnes) has already been mentioned in numerous articles. Diverting all the traffic to the nearby streets is very disruptive and time consuming. In addition, for those who have previously used the bridge every day, this situation is, timewasting. For example, the journey that would take 10 minutes before, takes about 25 minutes now. If we multiply (the difference) 15 minutes by the number of people using this bridge, there will be a huge figure that reflects the wasting of the time and money of the citizens.

But the fundamental question is;

"Do we expect all structures, regardless of their ages, to continue their $100 \%$ performance forever?" 
Structures, in one aspect, are like humans, but with a much longer lifespan. People are more efficient when they are young, but when they become old, they have less power and energy and use their abilities in a different way. We should treat the structures, the same. Structures are capable of working efficiently as they have been designed, when they are young. But over time, this capability would reduce, and it comes to the time that it would be reasonable, economically, to reuse these structures in a different way. In other words, we should find a way to retire them.

"Structures Retirement" does not mean that we are not going to use them, but we are deciding to reduce the loads on them to restore and use them for many more years.

Hammersmith Bridge, after 132 years of its continuous work and experiencing damages caused by bombings, seems to have reached its retired age. However, it can be used as a "Green Bridge" for a direct connection between Hammersmith and North Barnes. It can be used for pedestrian crossings and cycling efficiently. In order to connect the vehicular traffic, a new bridge can be constructed to meet the vehicular traffic needs of the area. Needless to say, that with the correct use of the existing bridge (less loading), it can live longer.

\section{COMPARE FOUR OPTIONS}

\section{OPTION 1: Keeping the existing Bridge as it is. No repairs:}

- Allows the existing bridge for pedestrians and cyclists.

- Carrying out no repairs to the bridge, so no need money to spend;

- Will not meet the vehicular traffic demands for now and the future meaning that several London bus routes are being diverted.

OPTION 2: Carrying out a partial repair to the existing bridge:

- Still does not solve the usage restrictions (e.g. 7.5t weight limit), due to concerns about the elderly structure, and restrict its weight load to only single-decker busses;

- Will not meet the increasing traffic demands in the future;

- This option financially is cheaper than the option 3.

OPTION 3: Fully repair the existing Hammersmith Bridge:

- Is very expensive (around $f 120 \mathrm{~m}$ according to early-stage estimation);

- Still does not solve the usage restrictions (e.g. 7.5t weight limit);

- Will not meet the increasing traffic demands in the future;

- And as the existing bridge is quite old, it needs to be repaired periodically, which would not be financially viable.

OPTION 4: Constructing a new bridge\& restoring existing:

- Needs to invest a substantial amount of money at the start, but will result in saving money for the future;

- Gives another alternative access between Hammersmith \& Barnes areas; 
- Allows the existing bridge to be a 'Green Bridge' for pedestrians and cyclists. It can be redesign as a Viewing Platform and Recreational Area as well;

- Will attract lots of tourists as a Point of Interest and boost the businesses located both sides; as has occurred with the Millennium Bridge to the east of the River Thames;

- It will be designed to meet future traffic loads requirements.

\section{PROPOSED BRIDGE FEATURES}

The new bridge will connect Great West Road (A4) from 'Furnivall Gardens' to the North Barnes. The land-take from Furnivall Gardens is around $1,550 \mathrm{~m}^{2}$, and the new bridge passing over the Thames River, it will use part of the St. Paul's school grounds (about $1,450 \mathrm{~m}^{2}$ ). The total length of the proposed road is about 400 metres and the length of the new bridge is about 260 metres. It is a three-span bridge.
$\checkmark$ North Span 35m
$\checkmark$ Centre Span 190m
$\checkmark$ South Span $35 \mathrm{~m}$

The new bridge can be much stronger and more secure and inspired by the architectural features of the existing Hammersmith bridge. The initial sketch provided can be used to meet the needs and inspiration of the existing bridge architectural features.

\section{EXISTING \& PROPOSED BRIDGE PLANS \& 3D SKETCHES}

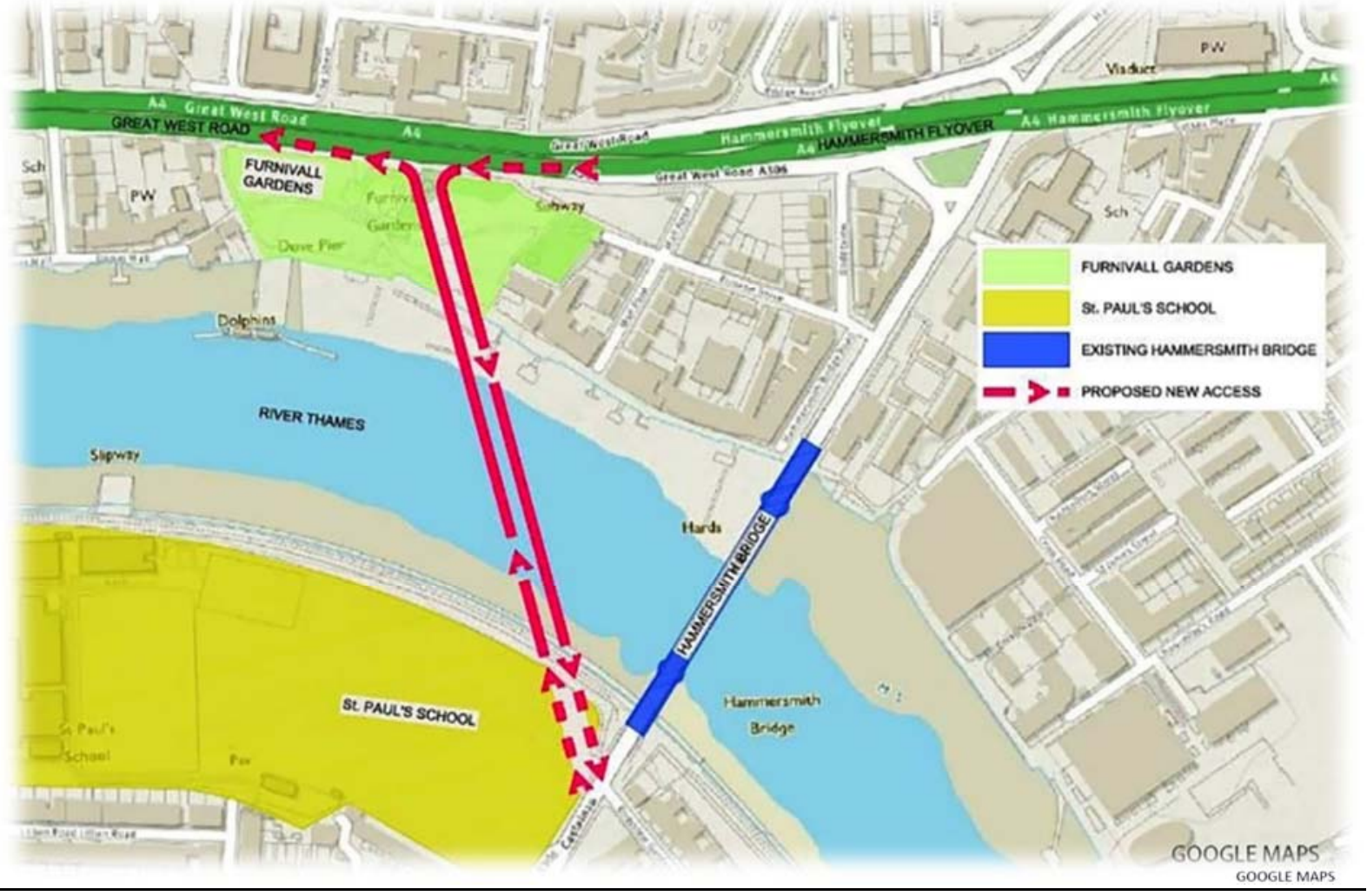

FIGURE 2: EXISTING PLAN SHOWING PROPOSED NEW ACCESS 


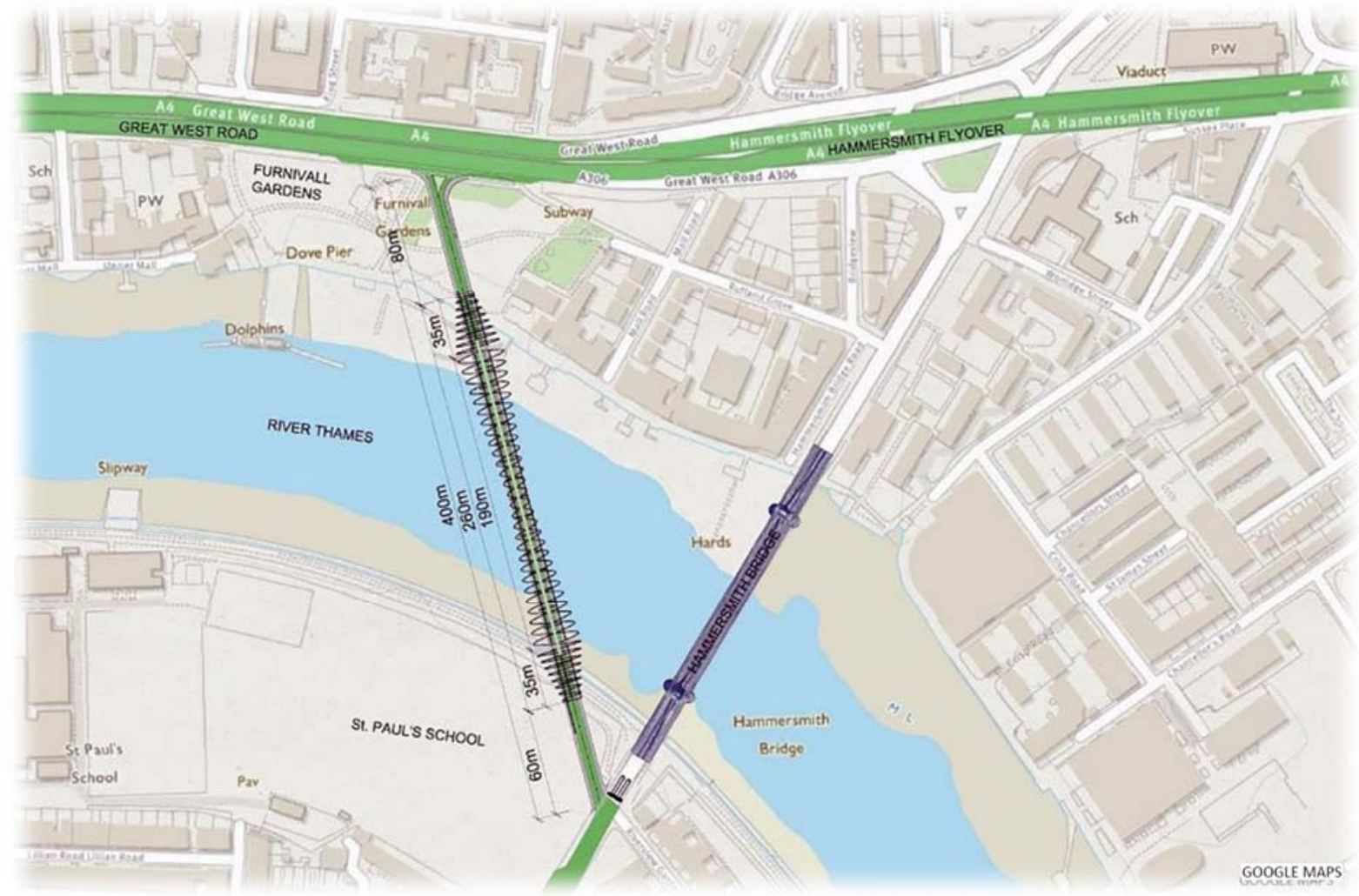

\section{FIGURE 3: PROPOSED PLAN}

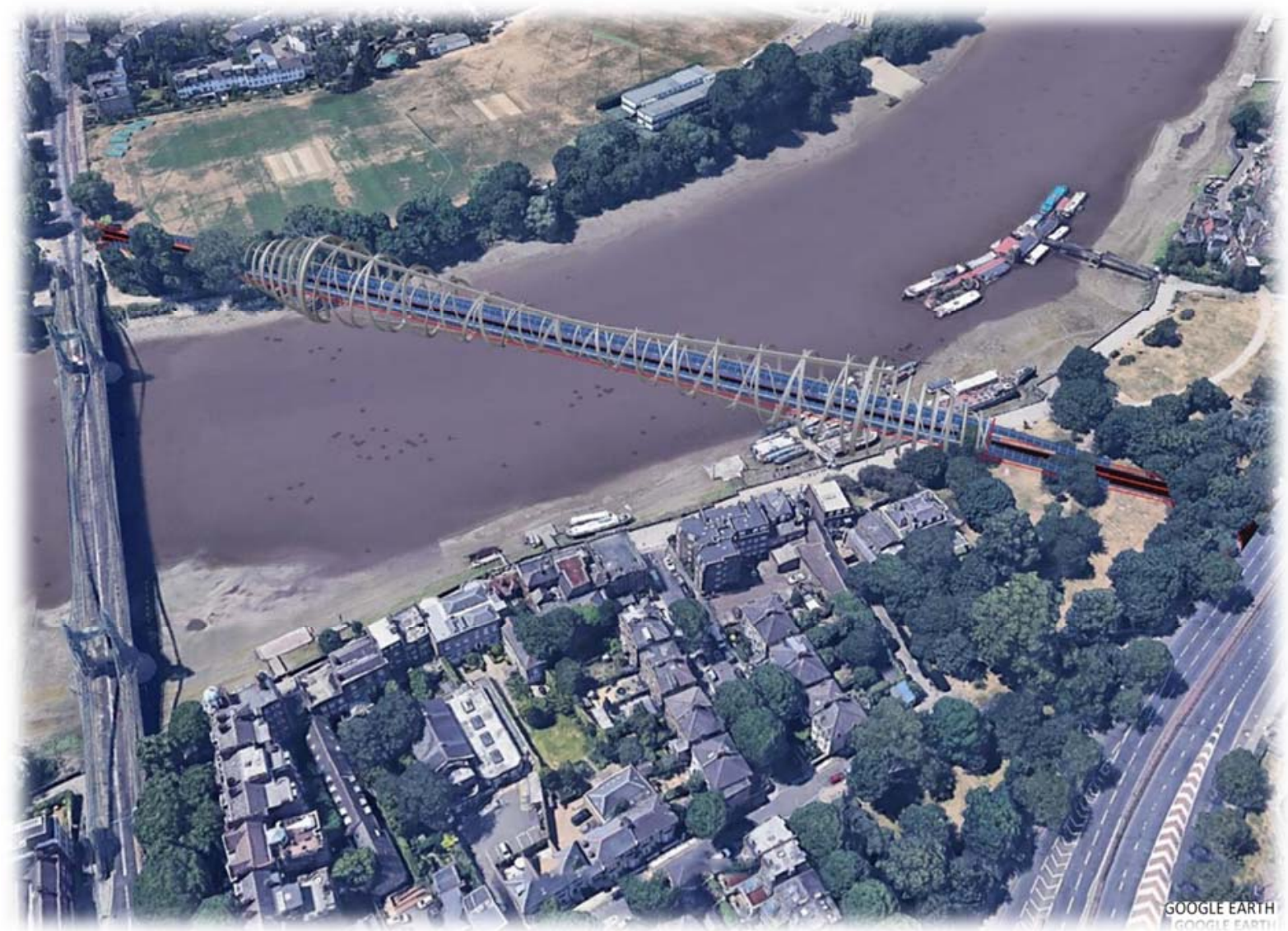

FIGURE 4: 3D BIRD'S EYE VIEW SKETCH 


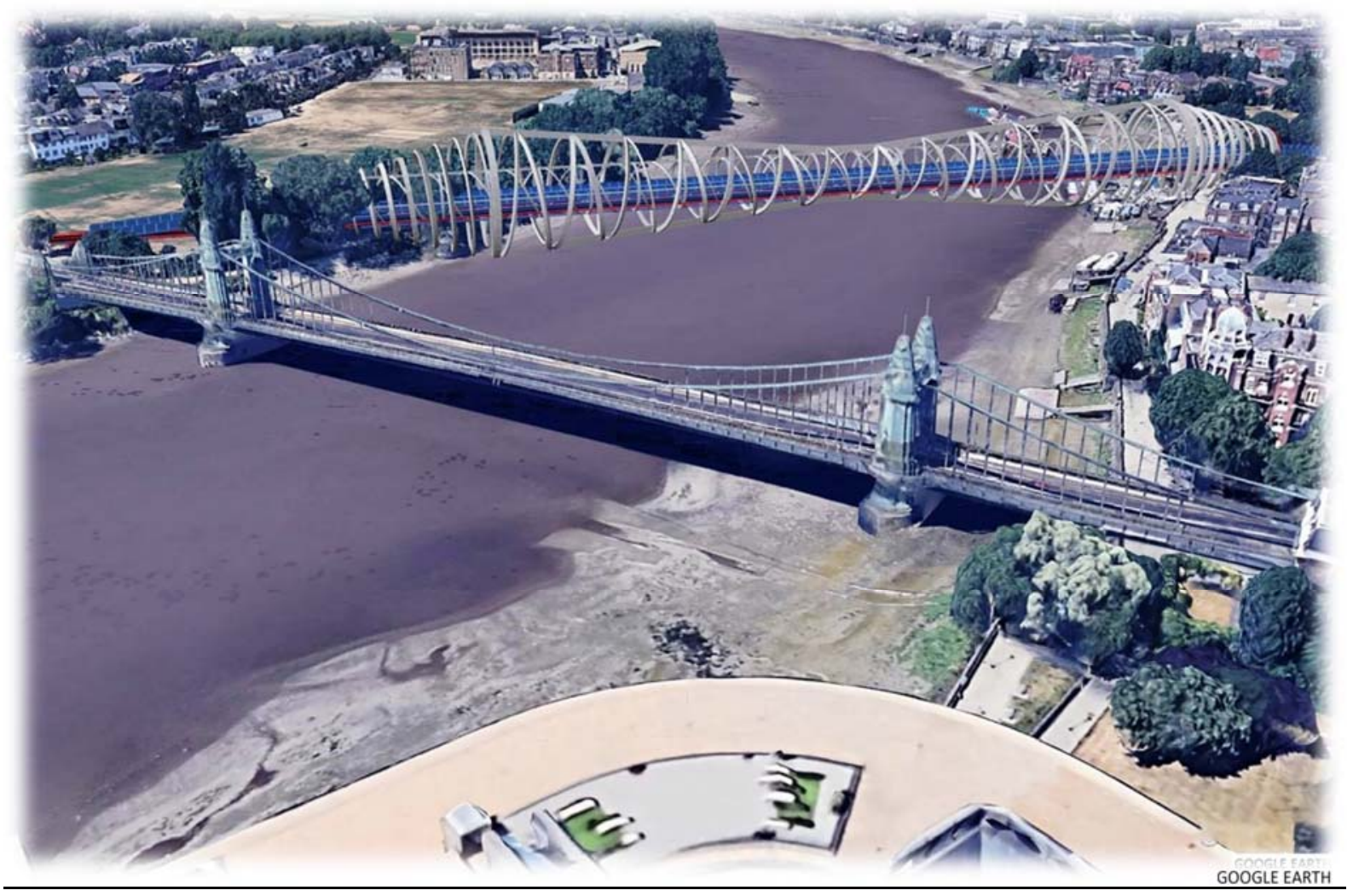

FIGURE 5: 3D VIEW

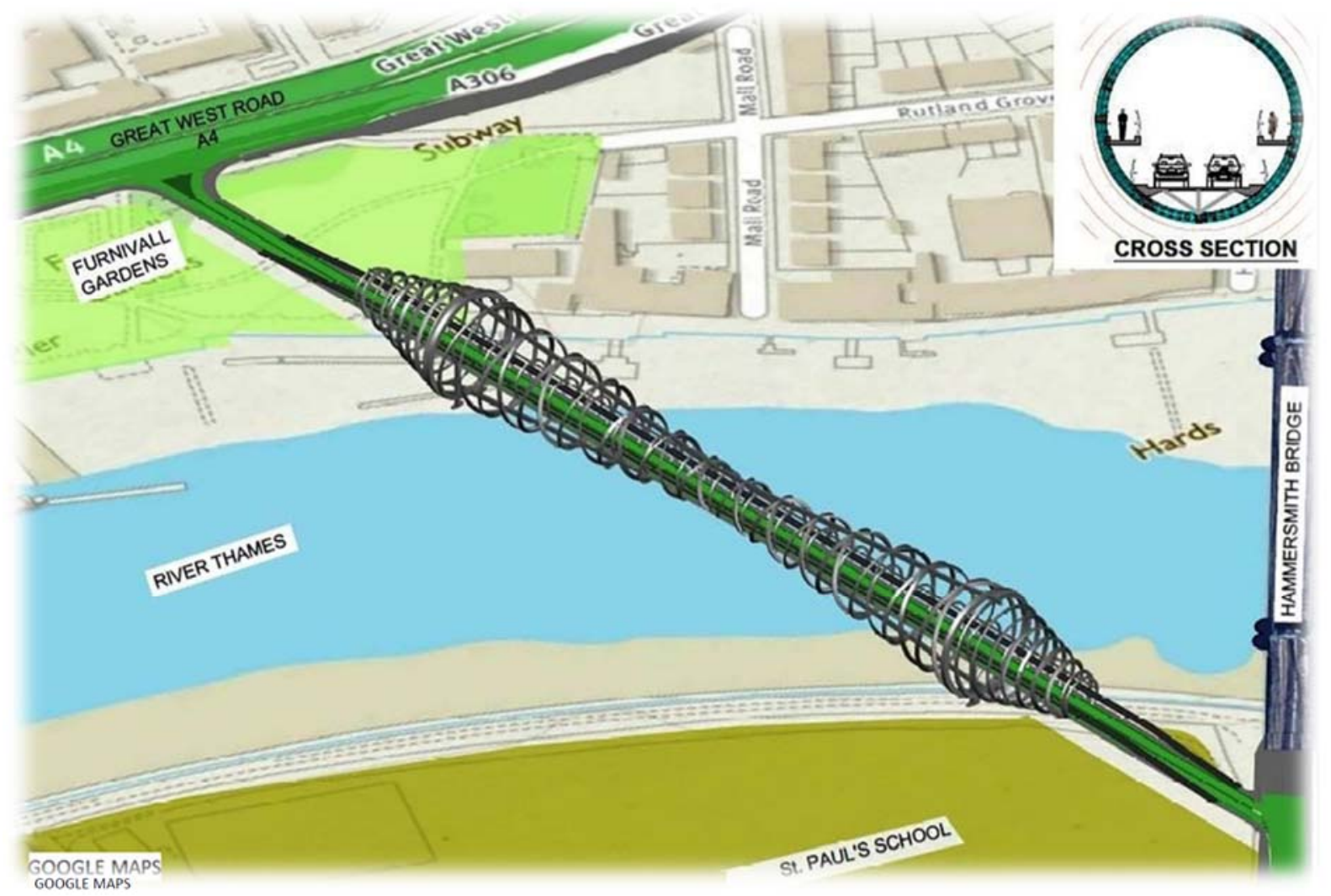

FIGURE 6: 3D VIEW \& CROSS SECTION 


\section{REFERENCES}

[1] Historicengland.org.uk. (2015). HAMMERSMITH BRIDGE, Hammersmith and Fulham - 1079819 | Historic England. [online] Available at: https://historicengland.org.uk/listing/the-list/list-entry/1079819.

\section{SOURCES}

- LBHF. (2016). H\&F Council statement on Hammersmith Bridge. [online] Available at: https://www.lbhf.gov.uk/articles/news/2016/09/hf-councilstatement-hammersmith-bridge [Accessed 15 Nov. 2019].

- Wikipedia Contributors (2019). Hammersmith Bridge. [online] Wikipedia. Available at: https://en.wikipedia.org/wiki/Hammersmith Bridge [Accessed 15 Nov. 2019].

- Google Maps. (2019). Google Maps. [online] Available at: https://maps.google.ca/.

- Google Earth. (2000). Overview - Google Earth. [online] Available at: https://earth.google.com/.

- En.wikipedia.org. (2019). Cable-stayed bridge. [online] Available at: https://en.wikipedia.org/wiki/Cable-stayed bridge [Accessed 15 Nov. 2019].

- Horgan, R. and Horgan, R. (2019). Exclusive | Hammersmith Bridge could be permanently closed to motorists - New Civil Engineer. [online] New Civil Engineer. Available at: https://www.newcivilengineer.com/latest/exclusivehammersmith-bridge-permanently-closed-motorists-09-07-2019/ [Accessed 15 Nov. 2019].

- En.wikipedia.org. (2019). Northern Spire Bridge. [online] Available at: https://en.wikipedia.org/wiki/Northern Spire Bridge [Accessed 15 Nov. 2019].

- Hammersmith Bridge Assessment Report. (2013). Reading: Thames Water Utilities Limited.

- Hot Rails. (2019). An empirical rough order of magnitude cost function for bridge structures. [online] Available at: http://hotrails.net/2014/09/an-empiricalrough-order-of-magnitude-cost-function-for-bridge-structures/ [Accessed 15 Nov. 2019].

- Bing Maps. (2020). Bing Maps. [online] Available at: https://www.bing.com/maps [Accessed 15 Nov. 2019]. 